\title{
NA TUBERCULOSE, COMO CUIDAR?
}

\section{JANAINA APARECIDA DE MEDEIROS LEUNG ${ }^{1}$ FÁTIMA TERESINHA SCARPARO CUNHA ${ }^{2}$, AFRANIO LINEU KRITSKI ${ }^{3}$}

Programa de Pós-Graduação em Clínica Médica, Faculdade de Medicina Universidade Federal do Rio de Janeiro, Av. Brigadeiro Trompowsky s $/ \mathrm{n} ., 11^{\circ}$ andar 21941 -590, Ilha do Fundão (Cidade Universitária) - Rio de Janeiro - RJ - Brasil

\author{
janainaleung@hucff.ufrj.br, fatima.scarparo@gmail.com, \\ kritskia@gmail.com
}

\begin{abstract}
Resumo. No presente estudo analisamos os discursos dos sujeitos sobre adoecimento de tuberculose (TB), prevenção e tratamento da infecção latente por tuberculose (TILTB). Foram entrevistados cinco sujeitos que iniciaram o TILTB, pelo convívio com alguém adoecido por tuberculose (TB), mas não o concluíram atendido num centro de referência de TB no Rio de Janeiro, Brasil. Discute-se, pela Análise de Discurso de matriz francesa, a singularidade de cada sujeito, interpelados pelas ideologias. Apesar da incompletude da língua e dos sujeitos, os estudos discursivos contribuem na saúde para o cuidado diário, no atendimento no ambulatório de TB, com olhar atento a diferenciação social, violência territorial e a invisibilidade do sujeito no processo de elaboração do projeto terapêutico.
\end{abstract}

Palavras-chave: tuberculose pulmonar; tuberculose latente; linguagem; assistência centrada no paciente.

\begin{abstract}
In the present study, we analyzed the subjects' speeches about tuberculosis disease (TB), prevention and treatment of latent tuberculosis infection (TILTB). Five subjects were interviewed who started treatment for (TILTB) because of close contact with someone sick of tuberculosis (TB) but did not complete it, attended at a TB reference center in Rio de Janeiro, Brazil. The Discourse Analysis of the French Matrix discusses the uniqueness of each subject, permeated by ideologies. Despite the incompleteness of the language and the subjects, discursive studies contribute to daily care health, in the service at the tuberculosis clinic, with an attentive eye to social differentiation, territorial violence and the invisibility of the subject in the process of elaborating the therapeutic project.
\end{abstract}

Keywords: pulmonary tuberculosis; latent tuberculosis; language; health production; patient centered care.

\footnotetext{
${ }^{1}$ Mestre em Ciências da Saúde pla UFRJ. Programa de Controle da Tuberculose Hospitalar, Instituto de Doenças do Tórax/Hospital Universitário Clementino Fraga Filho, Universidade Federal do Rio de Janeiro. ${ }^{2}$ Doutor em Saúde Coletiva pelo Instituto de Medicina Social da Universidade do Estado do Rio de Janeiro. Professora Associada da Universidade Federal do Estado do Rio de Janeiro.

${ }^{3}$ Professor Titular da Faculdade de Medicina da Universidade Federal do Rio de Janeiro. Programa de Controle da Tuberculose Hospitalar, Instituto de Doenças do Tórax/Hospital Universitário Clementino Fraga Filho.
} 


\section{CONSIDERAÇÕES INICIAIS}

A tuberculose pulmonar (TBP) é uma doença que acomete as pessoas tanto no Brasil quanto no mundo. Na linguagem biomédica, os sintomas mais frequentes, manifestados no corpo, pela presença do Mycobacterium tuberculosis, são tosse, emagrecimento, febre e cansaço. No atendimento ambulatorial o cuidado diário acontece no encontro com a pessoa adoecida por TBP, e outros sentidos circulam, durante a interação, para além do técnico-científico. Quem vivencia a doença, no seu cotidiano familiar e social, apresenta outros sentidos marcados por estigmas, preconceitos, devido à circulação do discurso quanto à transmissibilidade que o afasta temporariamente das atividades sociais, educacionais e laborais pelo risco de adoecimento das pessoas próximas ao seu convívio. Destaca-se que aqueles que convivem com o sujeito adoecido são classificados como contatos de tuberculose.

O discurso na área da saúde sobre a tuberculose pulmonar tem elementos da própria historicidade da doença, em que, antes da introdução do esquema medicamentoso na década de 50 do século XX, a terapêutica era baseada em isolamento até a morte. Impor o uso da medicação está alicerçado no conceito de ruptura da transmissibilidade e subsidia as ações de saúde em controlar o sujeito para o combater a doença. Desta forma, as ações de vigilância em saúde estabelecem estratégias para atenção ao sujeito adoecido com medidas diretamente relacionadas ao cumprimento do tratamento, com regularidade no uso da medicação, presença às consultas ambulatoriais e execução dos exames para avaliação do seguimento terapêutico, de acordo com os protocolos instituídos pelo Ministério da Saúde (MS) apresentados no Manual do Programa Nacional de Controle da Tuberculose (PNCT) (BRASIL, 2018).

Contudo, questiona-se como a pessoa adoecida por TBP se apresenta nesse processo assistencial: ela está integralmente inserida no cuidado ou assistida por um sistema disciplinador e protocolar que estabelece o cumprimento de regras, como um mecanismo de vigilância e controle para que se evite o risco de transmissão e adoecimento de outras pessoas? Dentre as atividades estabelecidas pelo PNCT para o controle da doença, destaca-se a avaliação dos contatos de paciente com TBP para a identificação precoce da TB ou da infecção latente por tuberculose (ILTB). Em ambos os casos, a pessoas relacionadas como contato pelo paciente no momento do seu atendimento são orientados a realizarem exames e o acompanhamento, ou conforme avaliação individual, selecionados para o tratamento da ILTB, com objetivo de reduzir a possibilidade de adoecimento. Segundo estudos no campo da epidemiologia, o risco e a probabilidade de adoecimento estão associados ao contato com o bacilo na interação do paciente com o seu núcleo de convivência diária, seja na família, no trabalho ou no convívio social, e também se articula ao tempo de exposição e aos fatores de imunidade de cada sujeito (BRASIL, 2018; CDC, 2013; BREIHL, 2006).

O discurso epidemiológico na TB amplifica o objeto de estudo, traz o poder e a ordem na constituição do enunciado em que os contatos de alguém com a doença estarão determinados ao adoecimento, cumprindo o papel da necessidade de tratamento, o qual se resume em determinar um saber estruturado, exercendo poder simbólico a partir da construção de um estudo técnico, projetando aos sujeitos uma concepção homogênea e hegemônica de uma realidade construída, sem considerar os aspectos sociais, psicológicos e ambientais. Não se trata de descartar os estudos epidemiológicos na 
tuberculose, mas não os considerar como totalitários, norteadores de estratégia ou condutas, nem exclusivos para o cuidado e práticas afins, pois os determinantes sociais estão presentes neste campo do saber são apagados do processo saúde-doença (BORGHIN et. al., 2018; BOURDIEU,1989; BREILH, 2006).

A linguagem na tuberculose, ainda se apresenta no controle ao outro, no poder que 'criminaliza' individualmente o sujeito por suas ações, o anula do processo terapêutico, e retira sua capacidade e responsabilidade pelo autocuidado. Este discurso materializa a formação discursiva da ideologia sanitarista, epidemiológica. A formação discursiva é a manifestação no discurso das ideologias nas quais o sujeito é interpelado. Com este posicionamento exime o Estado de sua responsabilidade pela execução da política de saúde com inclusão social. Posicionamento este, validado pela política atual do país, em que os direitos sociais são retirados, o sistema de saúde é desmantelado, e a promoção de reformas incidem diretamente na determinação social da doença.

Nos protocolos de atendimento na TBP, o adoecimento é materialização da linguagem biomédica sobre o corpo do Outro, é o discurso universal, homogêneo da transmissão, morte, do corpo frágil, febril, emagrecido, ou seja, um discurso que não desloca para outros sentidos. Porém, cada indivíduo interpelado pela ideologia irá se constituir em sujeito de sentidos e desloca do discurso universal dos efeitos do adoecimento no corpo, para sua relação com a exterioridade, ou seja, o sujeito afetado pelo inconsciente traz a questão da não-unidade e não-homogeneidade. Assim, o adoecimento no corpo será sentido de maneira única, particular, individual e intransferível, a partir da sua relação do "eu" com o Outro, do corpo com a linguagem, no seu território, na sua comunidade, o sujeito não enuncia o "eu” (ORLANDI, 2013; GUIMARÃES, 1998; RAVANELLO, 2018). Quando o Estado deixa de assegurar a proteção social com a garantia dos direitos constitucionais, e se isenta em fazer políticas públicas de saúde, desloca o sujeito numa posição de "não" cidadão, e age sobre ele os efeitos da doença no corpo e na sua vida, pois particulariza o problema, atribuindo ao próprio sujeito a responsabilidade integral pelo seu adoecimento.

Pensando no atual modelo de assistência à saúde do sujeito adoecido por tuberculose, questiona-se se esse indivíduo é visível ao sistema e como sua vida está inserida na assistência e nos protocolos instituídos. A Organização Mundial de Saúde (OMS) estabeleceu a Estratégia STOP-TB com três pilares para acabar com a epidemia global da doença: 1. ações de cuidado e prevenção, centrados no sujeito; 2. políticas ousadas e sistemas de apoio, com ênfase na proteção social de populações vulneráveis; e 3. intensificação da pesquisa e inovação. Nesse contexto, colocar o sujeito como protagonista do processo terapêutico pode ser a chave para o desenvolvimento de políticas de proteção aos sujeitos adoecidos por tuberculose. Por conseguinte, uma vez que seja dada atenção e visibilidade aos vulneráveis, será possível o desenvolvimento de ações, a partir destes e para estes, além de estimular pesquisas e ensino acerca da melhoria do cuidado na tuberculose (BRASIL, 2018).

Compreender e atuar no sistema de saúde, a partir de um sujeito protagonista nas práticas do cuidado, sem subjugação, vitimização, culpabilização e disciplinarização dos corpos, é colocá-lo como centro do processo, trazendo oportunidades para suas potencialidades de vida e seus desejos. É tornar possível sua decisão no processo de tratamento junto com a equipe profissional de saúde, a partir de uma relação de reciprocidade, na qual ambos 
estejam atentos à escuta e à valorização das singularidades. Pode ser assim, uma maneira diferenciada do cuidado em tuberculose (GUATTARI; ROLNIK, 1986).

No exercício diário do cuidado com sujeito adoecido, se questiona como esse cuidado mobiliza os sentidos e faz com que os contatos de TBP interrompam o tratamento: quais os efeitos de sentidos atribuídos por este sujeito sobre adoecimento e prevenção?

Este artigo é resultado do trabalho de campo com 5 participantes escolhidos a partir de informações de um estudo quantitativo (AGUIAR, 2014). Trata-se de um grupo selecionado, com sujeitos que tiveram tuberculose e que são classificados pelo PNCT (MS) como contatos de sujeitos com TBP, que decidiram não dar continuidade ao tratamento para ILTB. Os participantes trazem, nos seus discursos, as suas relações com a tuberculose, e expressam os efeitos de sentidos produzidos pela doença no seu cotidiano, no seu corpo, nos seus afetos e relacionamentos, e nas suas relações com os trabalhadores da saúde. Nos encontros em que ocorre a interações entre os sujeitos, podemos entender o deslocamento dos sentidos predominantes, que circulam de modo autorizado pelo saber médico referente à doença, e como os sujeitos são colocados em ação no processo de cuidar.

O objetivo do presente estudo foi analisar as narrativas da descontinuidade do tratamento para (ILTB) nos contatos de alguém adoecido por TBP, e quais os sentidos produzidos pela doença e pela prevenção. Os sujeitos selecionados expressaram que a decisão não se reduz à classificação epidemiológica de abandono, pois isso seria inferir que o valor que esse sujeito atribui é equivalente às ações programáticas para o controle da doença. $\mathrm{O}$ abandono, quando vivido pelo sujeito, aponta para outros sentidos, demonstrados pelo posicionamento dos sujeitos, em assumir a responsabilidade do seu cuidado, com a tomada de decisões e definição das suas prioridades cotidianas, rompendo com discurso universalizante, e com o interdiscurso de uniformizar e padronizar sujeitos, por si, singulares. As narrativas produzem sentidos para o cuidado que aponta para vida, território, espaço social, assim podemos olhar por outro ângulo o conceito do abandono do tratamento (ORLANDI, 2013).

\section{TUBERCULOSE: ADOECIMENTO E PREVENÇÃO}

A Análise de Discurso (AD) de Michel Pêcheux possibilita a produção de sentidos pelos sujeitos a partir das suas vivências e da interação com o Outro, uma vez que o discurso está circunscrito ao mundo onde se vive na história, no contexto social, marcado por suas ideologias (ORLANDI, 2013; PÊCHEUX, 2009).

A AD nos permite compreender a mediação entre o homem e a realidade natural e social, materializada em seu discurso. Apresenta como o sujeito produz o seu dizer, sob quais condições vivencia suas experiências reveladas nas contradições e resistências, pois a linguagem não é transparente, os sentidos não são conteúdos estagnados em síntese e sintaxe, ou seja, os sentidos não estão definidos, são inacabados, mudam de acordo com as formações ideológicas do sujeito, que é afetado pela língua e história e (re) significam. O discurso não é totalmente livre, nem totalmente determinado por mecanismos exteriores (TFOUNI, MONTE-SERRAT, CHIARETTI, 2011; ORLANDI, 2013). 
A língua é a condição do discurso, é a base para construção do processo discursivo, onde uma só língua para várias culturas. O processo discursivo é a relação do histórico e social, e a tomada de posição do sujeito pelo seu discurso, na $\mathrm{AD}$ não se trata apenas de transmissão da informação, mas inesgotáveis maneiras de produção de sentidos. $\mathrm{Na}$ tuberculose o posicionamento, frequentemente encontrado, no discurso dos trabalhadores da saúde, é o da necessidade do controle da tuberculose por se tratar de uma doença que foi declarada como emergência mundial com atenção fortemente marcada aos indicadores epidemiológicos que mapeiam a tuberculose no Brasil e no mundo, traz para $\mathrm{o}$ atendimento o já-dito sobre a doença e as suas consequências. Nesse contexto, o Estado exerce sobre o corpo do Outro um poder de vigilância e de propriedade, apagando o sujeito do projeto terapêutico. Com isto, se exime das responsabilidades em assegurar os direitos sociais que possam contribuir para o sujeito mobilizar suas próprias ações para seu autocuidado. É necessário conhecer como o discurso circula no cotidiano social, no território de quem convive com a doença, e, nos apresentar novos sentidos no contexto sócio ideológico, para que possamos vislumbrar outro caminho para o cuidado na TBP (ORLANDI, 2017; FOUCAULT, 2008).

No tratamento preconizado pelo MS à ILTB, a partir dos dados epidemiológicos, a finalidade é a prevenção do adoecimento por tuberculose em populações. O MS estabelece que a realização do tratamento da prevenção, contempla indivíduos contatos de uma pessoa com tuberculose, pessoas vivendo com HIV e outras pessoas com imunidade comprometida. Para definir quem fará este tratamento, realiza-se a Prova Tuberculínica, que é a inoculação da proteína RT-23 nos contatos, com leitura do resultado após 72 horas. O resultado igual ou maior que cinco milímetros $(\geq 5 \mathrm{~mm})$ irá direcionar a conduta terapêutica medicamentosa para o tratamento da ILTB (BRASIL, 2018).

$\mathrm{Na}$ cidade do Rio de Janeiro, predominantemente, o acompanhamento da prevenção é realizado na atenção básica, em unidades da Saúde da Família. Estes sujeitos são, em geral, moradores em aglomerados (favelas) dominados pelo tráfico ou por milicianos, cenário que traz cautela e temor para a circulação de profissionais de saúde, que em muitos momentos têm suas atividades interrompidas pela violência. Conhecer os detalhes do cuidado em saúde no cotidiano destes sujeitos e a sua rede de atenção, é um desafio constante, que consiste no entrelaçamento das equipes de saúde com a população local e as características de cada região, para assim construir um acompanhamento em conjunto, tanto da TBP, quanto da ILTB. A OMS projeta seu foco de ação no longo prazo (20162035) para redução da incidência da TB no mundo, mas o cuidado não deve se limitar em traçar estratégias rígidas para o cumprimento de metas, e sim voltar à atenção ao usuário, e como as ações são recebidas e percebidas por ele, no seu território. Estas devem estar centradas neste sujeito, a partir das suas narrativas, capazes de mobilizar sentidos que estão para além dos manuais e relatórios recomendados, de conhecer sua vida e trazer suas dificuldades para o debate tanto acadêmico, quanto profissional. Tudo isso aliado às ações do Estado que possibilitem expansão e melhoria nas suas condições de vida.

Os cinco sujeitos que aceitaram participar do estudo estão identificados por A1, A2, A3, A4 e A5, foram entrevistados em suas residências ou em locais indicados por eles, o que permitiu distanciá-los da imposição das informações circulantes, predominantes no interior do ambulatório especializado em TB. Após a leitura do material transcrito, a analista selecionou os recortes do corpus discursivo definidor para construção da análise. 
O recorte é uma unidade discursiva, fragmentos relacionados linguagem-situação e a partir deste que são destacadas as sequências discursivas que irão compor a análise (FERNANDES, 2019).

Uma das sequências discursivas ${ }^{4}$ revelou a naturalização da doença no cotidiano deste sujeito, como mais um fato presente na comunidade, sem que houvesse estranheza ou culpabilização diante da descontinuidade do tratamento da ILTB, pois os agravos sociais aos quais ele e a comunidade estão submetidos tornam a TBP reconhecida tão somente como mais um desafio a ser vencido. Nesse contexto, o sujeito percebe que a continuidade da vida é mais significativa do que a continuidade do tratamento preventivo da TB. $\mathrm{O}$ cotidiano da violência em áreas do território da cidade do Rio de Janeiro, a guerra em decorrência do tráfico de drogas e de armas e a supressão do direito de circulação no território são fatos que revelam a negação dos direitos instituídos na Constituição Federal do Brasil de 1988, e do acesso às condições que possibilitem a vida com dignidade e proteção (BRASIL, 1988).

A doença, nesse contexto, é mais uma condição a ser vivida e não prontamente resolvida. A atenção do sujeito está centrada nos fatos territoriais vivenciados no cotidiano, tal como se confirma na fala destacada, após a chegada das pesquisadoras à comunidade para realização da entrevista.

Recorte $\mathrm{n}^{\circ} 1$

Preocupação com a violência na comunidade e prezava por integridade física de vocês, recente tiroteio, temia pela segurança de vocês, preocupada com a família de vocês e medo de estar na comunidade e acontecer alguma coisa. (A5)

A produção do conhecimento em pesquisa qualitativa não trabalha com controle das variáveis, é a imersão no território desconhecido e as produções de vida existentes que nos interessam. O pesquisador não é neutro, produz ação política, ativa, contamina-se ao dar passagem ao saber do usuário, um saber não dominado, não hierarquizado. É preciso compreender os sentidos para extravasar o limite geográfico e enxergar o usuário em si mesmo, território existencial, subjetivo e cultural, se alinhando a outros espaços a partir do encontro com o outro, e o efeito por este produzido (FREIRE et. al., 2016)

A sequência discursiva de A5 apresenta a preocupação da moradora da comunidade com a vida das pesquisadoras. A estranheza foi relatada porque duas profissionais quiseram entrevistá-la em seu território, o que implica procedimentos para entrar na favela e chegar a sua casa, um dos quais é entrar junto com o morador. É justamente nesse momento que surge o diferente ao território, o inquietante: o "estrangeiro". Estrangeiro ao território, alicerçados do conhecimento técnico-científico, com seus saberes, suas preconcepções e conceitos, mas que busca no encontro com o outro a construção de conhecimento por uma via compartilhada (nós e os sujeitos a quem nos propomos cuidar), nos aponta para outro olhar daquele território que está na mesma cidade, mas num espaço distante, também estrangeiro para nós, pois a circulação do discurso na mídia tradicional é de insegurança e pessoas a serviço do crime. Ser o estrangeiro naquele momento nos apontou para os

\footnotetext{
${ }^{4}$ Sequências Discursivas - São as sequências orais produzidos pelo sujeito ou sujeitos a partir das condições de produção do discurso, procedentes dos recortes definidos pelo analista, que reunidas, irão constituir o corpus discursivo para a análise (COURTINE, 2009 [1981], p. 107-108).
} 
sentidos de invisibilidades e exclusão dos direitos sociais, vivenciados por àquela população no seu cotidiano (FREIRE et. al., 2016).

A interpretação de um texto, recorte, a análise de discurso não é realizada como na hermenêutica, nem descreve a sintaxe. O objetivo é compreender como o texto produz sentido, as posições dos sujeitos em que se inscreve em uma formação discursiva e não em outra, o sentido não se reduz em si, é um jogo no sócio-histórico, na relação com a ideologia. As formações discursivas representam no discurso as formações ideológicas, e os sentidos são determinados ideologicamente. É o lugar dos sujeitos em si, dos sujeitos com os lugares que ocupam no social e do discurso já-dito (ORLANDI, 2013; FERREIRA, 2001). O Recorte 1 apresenta uma parte da vida na comunidade, o discurso posiciona o sujeito do local de pertencimento e os sentidos produzidos. A formação discursiva do $\underline{\text { medo }}$, opressão, vivenciadas no cotidiano da comunidade, a violência e as regras impostas por leis próprias locais, o controle da circulação territorial, e o sentido de que nada pode acontecer com alguém diferente ao território, aponta para refletir que sua vida e de seus familiares também poderiam estar em risco, pelas implicações em receber alguém "de fora" representante da universidade, e se algo acontecesse poderia chamar para uma possível intervenção policial na área e gerar, consequentemente, problemas com a gerência do tráfico.

Vivenciamos a dificuldade em circular naquele território e o direito de ir e vir limitado, como nos fala a entrevistada nas inúmeras vezes em que não pode sair de casa, devido à troca de tiros entre facções rivais, ou entre estas e os agentes da segurança pública do Estado, quando fazem incursões para repressão ao tráfico. Ao viver esse encontro, o profissional de saúde pode vir a se questionar sobre os limites do processo de cuidar fundado exclusivamente nos indicadores epidemiológicos e/ou nas metas a serem cumpridas. Cuidar é um processo complexo voltado para a vida do sujeito.

O participante A5 relaciona as situações que fundamentaram sua decisão em não dar continuidade ao tratamento, que devem ser consideradas no momento da elaboração do projeto terapêutico. O modelo de tratamento presente na ideologia de que a TBP é uma ameaça, e o seu controle é uma luta constante, uma 'guerra' a ser vencida, leva à anulação do sujeito durante os encontros nos serviços, porque os dizeres circulantes afirmam a incapacidade desse sujeito em decidir sobre seu corpo e sua vida, e mostram a necessidade real de políticas públicas de saúde que sejam sensíveis a este sujeito.

A prática assistencial está estruturada em não ouvir as questões da vida do sujeito, descaracterizando-a como vida, e o inserindo num modelo universal e pragmático, apagando a produção da sua existência e moldando sua singularidade (LOREY, 2012, p. 14 em WASSER, 2016, p. 6), afirma que, sob o neoliberalismo, a desestabilização e a descaracterização do sujeito foram normalizadas, ou seja, colocar a vida na precariedade é efeito e suporte da nova governabilidade, que não vê a necessidade de revogar as desigualdades, distribuídas nas organizações e sistemas de controle social, e impossibilita o sujeito no desenvolvimento de suas potencialidades ao instaurar a ameaça pela tática da incerteza. A política de saúde vigente torna a vida precária e se apoia nas incertezas, no medo e na insegurança para promover o controle sobre o outro a partir da regulação da subjetividade, a qual deve ser repensada no cuidado ao sujeito (WASSER, 2016). 
O valor da vida para profissional de saúde se relaciona com o sujeito nas suas condições de existência, pois a universalização de práticas sistematizadas de assistência com códigos sociais produzidos/reproduzidos pelo Estado e sociedade, regulam e criam regimes de verdade sobre ambos. Produzir cuidado é dar visibilidade ao sujeito e ao plano de cuidado, misturar-se ao outro na produção da vida em seu território, porque o corpo está diretamente imerso no campo político, e marcado pelas relações de poder. É considerar o percurso social, histórico, ideológico de cada sujeito na unidade de saúde que também produz sentido, numa materialidade dura e institucional, tanto nos profissionais de saúde, como nos usuários. É romper o regime instituído, vislumbrando encontros sem imposição ou domínio de um saber sobre o outro, mas sim a reciprocidade entre os sujeitos (TFOUNI, MONTE-SERRAT, CHIARETTI, 2011; ABOURIN, 2008).

O instituído para a assistência à tuberculose está centrado na doença e se configura em atenção aos métodos diagnóstico, indicadores epidemiológicos, tratamentos medicamentosos, que asseguram uma prática científica, porém, não são decisivos no processo de cura nem no desejo do sujeito acerca do tratamento.

\section{Recorte $\mathrm{n}^{\circ} 2$ \\ O irmão da minha vizinha estava doente de tuberculose, ela explicou sobre a necessidade de ir ao hospital (... pausa) eu disse pô (...), tuberculose? (... pausa) mas tudo bem! Eu fiquei assim com medo porque tuberculose ela mata, né? Não lembro porque parei o tratamento ${ }^{5}$, parei pra cuida da minha mãe que teve câncer, na época davam até dinheiro da passagem, era tranquilo. [sorrindo]. (A5)}

As palavras refletem sentidos já proferidos, realizados de alguma maneira, presentes na história, na ideologia. Os sujeitos do discurso estão posicionados em determinado lugar de fala, e o seu discurso se estabelece com a relação de dizeres presentes - interdiscurso. É o modo como o sujeito significa em uma situação discursiva dada, apontando para outros dizeres na tuberculose, e não no modelo do discurso universal, que envolve tecnologias para diagnóstico e cura, mas que o sujeito social tem maior amplitude no processo do cuidado - sua história de vida (ORLANDI, 2013).

A análise do recorte revela uma sequência discursiva, onde o sujeito é atravessado pela ideologia do discurso voltado para as condições de produção impostas de ordem superior, e levando-o a apresentar o assujeitamento, o interdiscurso do medo, da gravidade, da transmissibilidade, e aponta a necessidade de combate e tratamento. No entanto, produz outro efeito de sentido no qual o sujeito A5 definiu prioridades e tomou decisões, que não incluíram o tratamento da ILTB. O interdiscurso sobre a necessidade em ir ao hospital está presente, e o sujeito é interpelado pela ideologia universal, e por um discurso procedente da clínica, o "já dito", sobre o risco para família e para a comunidade, e pautados nos significados da ideologia dominante do cuidado.

O sujeito ao falar da sua experiência e da maneira de viver com a Tuberculose revela em seu discurso a contradição entre os dizeres sobre a doença, trazidos por sua memória, que o posiciona como sujeito adoecido, como um perigo para si e para os outros, com riscos de transmissibilidade e morte. Por outro lado, ele rompe com esse discurso estabelecido, e mostra que a doença é marcada pelas desigualdades sociais, e que ele permanece com

\footnotetext{
${ }^{5}$ ILTB - Tratamento para Infecção Latente por Tuberculose.
} 
sua vida em movimento, e com suas prioridades e desejos. O trabalhador da saúde poderá assumir a posição-sujeito de agente do controle sobre o corpo, instituindo regras e comandos a serem executados pelo usuário, ou a posição-sujeito de cuidador, em que poderá deslocar os sentidos para outras formações discursivas, com o interesse pela vida do Outro (PÊCHEUX, 2009).

Os acontecimentos discursivos de A5 sobre o tratamento da ILTB, seus dizeres sobre a doença e a prevenção repercutem na sua ação, desloca o sentido para o seu desejo em não realizar o tratamento e estabelece a prioridade do cuidado ao outro. A5 não ocupa o lugar de sujeito-paciente, se posiciona como sujeito-cuidador e por suas escolhas, ainda que com o interdiscurso pulsante sobre morte e adoecimento.

\begin{abstract}
Recorte $\mathrm{n}^{\circ} 3$
Ah, eu sei que é uma doença... muito grave, uma doença contagiosa, uma doença que precisa ser combatida... Uma vez iniciado o tratamento você não pode abandonar... Não é? $\mathrm{O}$ tratamento é pesado... E eu sei que é uma doença que poderia estar erradicada e no entanto não está. Infelizmente. Fiquei muito preocupada, com muito medo. Porque, assim: eu trabalho numa escola, numa escola de classe média alta... Então você acha que por causa disso você tá meio que... o ambiente limpo e livre, né? Você acha que talvez num ambiente mais... que não tenha higiene, onde as pessoas não têm muito conhecimento, que é mais provável que exista esse problema lá. Então eu achei que estava meio que blindada nesse ambiente, né? E aí, uma professora... (...) filha de estrangeiros, morava em Ipanema, e ela tinha uma funcionária na casa dela, uma empregada que morava na Rocinha. E aí essa funcionária, né?, tossindo, achando que era uma gripe... tal. E aí de repente essa professora começou também ter os mesmos sintomas, tossindo... emagreceu. Aí, logo... Lógico: com um plano de saúde, foi logo procurar um médico. (A3).
\end{abstract}

O discurso revela a posição-sujeito de professora, com qualificação profissional e classificação social que a mantém distante da doença. O corpus traz a memória discursiva associada à transmissibilidade - "contágio" - e, por isso, deve ser combatida como uma guerra ao bacilo, representado pela ideologia sanitarista, e aquilo que pode vir a ameaçar a classe social que detém poder - "média alta" - e estabelece a elaboração e execução de ações e medidas de proteção imediatas. As formações ideológicas desse sujeito expressam que sua classe social está segura, pois a TBP se trata de uma doença grave, que mata e está presente predominantemente na população sem acesso aos direitos sociais, e que vive nas favelas e periferias das grandes cidades. De certa forma, podemos deslocar este discurso para o sentido de proteção, não por muros e/ou diferenciação favela-asfalto, mas por proteção social. É preciso lembrar que a tuberculose não está presa em um território determinado, que a saúde é direito de todos e dever do Estado, e que este Estado, precisa garanti-la, mediante políticas sociais e econômicas que visem à redução da doença e de outros agravos, assim como o acesso universal igualitário às ações e serviços para sua promoção, proteção e recuperação.

O sujeito A3 é interpelado pela posição ideológica, em que a classe social que ocupa, é decisiva para sua relação com a tuberculose e com o adoecimento. $O$ fato de seu local de trabalho estar em um território de classe média alta, como a própria define, lhe assegura uma sensação de proteção e de blindagem do contato com o agente causador da doença - 
Mycobacterium tuberculosis. Isso reflete como a memória histórica da tuberculose, que sustenta que a doença pertença exclusivamente a um determinado campo social, afeta este sujeito, indicando que o convívio com estudantes e professores de uma categoria classificada como média alta, pode lhe afastar de algo pesado e grave, como destacado no seu discurso. Porém, foi um sujeito pertencente a este grupo que possibilitou o contato com a TB, e a análise possibilita destacar que não existe blindagem quando se tem relações humanas, em que todos são iguais, equânimes, diante do contato com a doença transmissível, e da necessidade de tratamento. Assim, quando A3 refere-se à doença como "lá", expressa uma percepção de como a distância física entre as classes sociais e a diminuição dessa distância, tem expressão material real nas condições de vida, e torna-se inverso e complementar, pois a doença deixa de estar exclusivamente "lá" (WASSER, 2016; MONTAÑO, DURIGUETTO, 2011).

Conforme Dagognet (2012), o corpo do sujeito é atado ao corpo social, e a forma de sentir se reflete no cuidado com esse, e com os sinais apresentados em resposta à doença, destacando-se a diferença entre o tempo para busca desse cuidado, entre os sujeitos adoecidos: "E aí essa funcionária, né?, tossindo, achando que era uma gripe... tal. E aí de repente essa professora começou também ter os mesmos sintomas, tossindo... emagreceu. Aí, logo... Lógico: com um plano de saúde, foi logo procurar um médico" (A3). Em nossa sociedade, para muitos, a palavra igualdade não produz sentido, pois é a mesma doença em ambos os sujeitos, mas a forma como é sentida, como as pistas e sinais clínicos da doença são percebidas na variação do tempo se diferencia, pois cada um está inserido no seu corpo social e histórico (ORLANDI, 2017).

Portanto, um padrão importado, traduzido, e uniforme a seguir produz sentidos diversos, pois cada sujeito sente seu corpo de maneira que o conhece e o percebe, a partir do posicionamento diante da sua inserção no contexto sócio, histórico, cultural correspondente às características de cada grupo. A posição corpo-sujeito de cada indivíduo presente no discurso de A3, apresenta sentidos distintos: de um lado, ênfase no cuidado de si e, por outro, o apagamento do sentir do corpo, frequentemente apresentado nos discursos dos sujeitos em cuidado ambulatorial, que reconhecem a necessidade do afastamento das atividades diárias, principalmente do trabalho, mas não apresentam tal possibilidade aos seus empregadores por insegurança de serem colocados à disposição.

\section{TUBERCULOSE: O CUIDADO ACONTECE NO ENCONTRO}

O cuidado é relacionável com a bioética, no sentido do respeito à vida. Para cuidar, é necessário se expor ao outro, na sua condição "Ser"; e à compreensão integral do sujeito. A fábula de Higino ${ }^{6}$ diz que o homem está entrelaçado ao cuidado ao qual pertencerá enquanto ele viver, confundindo-se em uma só unidade, em que o homem é cuidado, integralmente. O homem, na totalidade, é o cuidado, e devido à temporalidade da vida, necessita deste para a manutenção da sua existência. A partir desse conceito, a promoção de estudos, pesquisas, e a elaboração de protocolos são ferramentas que orientam para preservação da vida. Entretanto, esta elaboração, não deve ser exclusiva, quando pensamos que no cuidado, o sujeito deve ser o protagonista das ações - "Dasein" - de Heidegger - "ser no mundo", é movimento, ação, imbricado no ser político, econômico e

${ }^{6}$ Caio Júlio Higino viveu em Roma entre os séculos I a.C e I d.C: "O mito do Cuidado" (MAIA et. al., 2009). 
social, e as pesquisas devem propor a discussão e construção do conhecimento para compreender que a política governamental tem que estar centrada nos sujeitos, com a promoção do cuidado de si e ao outro (MAIA et. al., 2009).

É no encontro, na interação entre os profisssionais de saúde e usuários e familiares, que os sentidos do processo de saúde-adoecimento podem ser ressignificados. Esse é um desafio para o diálogo entre os trabalhadores da saúde envolvidos na ação de cuidar, no encontro diário com o paciente e seus contatos no atendimento ambulatorial, quando se deve evitar a criação de estereótipos, junto aos posicionamentos desses sujeitos em relação à tuberculose. O sujeito adoecido deve se tornar visível ao grupo de profissionais que cuidam, com suas histórias de vida, de movimento, circulação, interação. Deve-se entender que o sujeito com TBP está além da doença, do tratamento, da prevenção da infecção latente, e até da sua não continuidade, e que no cotidiano do cuidado o profissional possa compreender a posição-sujeito do usuário e assegurar que este participe da programação terapêutica, e decida qual o papel que a doença irá assumir em sua vida.

Os sentidos não surgem de uma hora para outra, não existem em si mesmos, são determinados pela ideologia na qual o sujeito está inserido e nas relações sociais. Os sentidos são materializados no discurso, a análise dos enunciados nos apresenta a interpelação do sujeito pela ideologia, com suas referências vinculadas aos posicionamentos pré-constituídos, a respeito desse sujeito. O discurso é o lugar que se observa a articulação entre a língua e a ideologia, onde até o silêncio não é o vazio; ele fala, é interpretável e traz significados. Orlandi descreve o silêncio como o fôlego da significação, um lugar de recuo para que se possa significar, para que o sentido faça sentido, permita o movimento do sujeito, não é apenas o complemento da linguagem ou a pausa do discurso, já que ele tem significados próprios (ORLANDI, 2007).

O cuidado é extensivo para todas as áreas, no cotidiano do atendimento em saúde, tanto na rotina de assistência de saúde direta ao usuário, quanto na produção de pesquisas na área da saúde, sempre com atenção ao sujeito. O cuidado pode ser uma relação de forças, mas é marcado pelo movimento, no encontro com o outro, não é uma prática solitária. Cuidar é ter relação com o outro, ouvir o sujeito na sua "verdade" sem imposição de uma sobre a outra (FOUCAULT, 2010). No recorte a seguir, as formações discursivas nos apresentam o controle e domínio do usuário no momento da abordagem para sua participação num projeto de pesquisa com parceria internacional.

\section{Recorte $n^{\circ} 4$}

Aí chegaram pra nós nos dando uma folha, uma prancheta: Olha, você lê e se estiver de acordo você assina." Aí eu: "Mas como assim?!?

Não... Primeiro você entra naquela salinha ali que vai ter uma palestrazinha, a menina vai explicar pra vocês e tal... Aí mostrou pra gente um tubinho, tipo uma medicação, falou que aquilo não dava nenhum problema e não sei mais o quê... (A1)

Olha, pelo que tá aqui, é como se eu fosse cobaia de um projeto! De uma experiência! Aí ela deu meio um sorriso, né? Ela: Não, você não precisa ficar constrangida, não. Vocês não são obrigados a participar. E eu: Então tá, então... Ah, obrigada. Pelo amor de Deus! Aí eu falei: Ah, eu não quero, não. Ele: Eu também não tô gostando disso, não. Ser cobaia de uma coisa... que ia vir dos Estados Unidos. (A2) 
Os sujeitos A1 e A2 se posicionaram contra a participação do projeto de pesquisa e resistiram ao protocolo proposto. Analisando o recorte, a formação discursiva apresentada mostra que não houve encontro na saúde, não houve cuidado. Sabemos da importância de pesquisas na área da saúde, mas o cuidado com o sujeito não pode ser apagado do processo, onde foram classificados com abandonadores em virtude da sua posição-sujeito, pois assumiram a decisão de como cuidar dos seus corpos.

Alguns profissionais da área da saúde ainda possuem dificuldade em compreender e aceitar que o sujeito faz parte do processo decisório sobre seu corpo e sua vida. Observase que o poder da saúde apresenta dificuldade quando se depara com a resistência do sujeito. A permissão do outro sobre si é uma relação entre o uso que fazemos da nossa razão, e dependerá do próprio sujeito e da relação de autonomia consigo mesmo. $\mathrm{Na}$ Análise de Discurso, não há julgamento com quem está a conduta acertada e a decisão a ser tomada, mas sim o movimento que o sujeito traz materializado em seu discurso; tratase em discutir a sua participação no seu cuidado, desde o planejamento até a realização (FOCAULT, 2010).

A produção do cuidado acontece no trabalho vivo, no ato do encontro, nas relações e interações entre os trabalhadores da saúde e usuários. No momento em que os sujeitos se encontram para a produção do cuidado, deve ser construído o projeto terapêutico em conjunto, com os saberes oriundos de ambos os sujeitos - cuidador e sujeito a ser cuidado, com escuta atenta aos sentidos produzidos por estes quanto à tuberculose, sem imposição dos saberes e/ou ações do sujeito ao Sujeito, um mesmo sujeito é o outro. O eu está descentrado, não está fechado em $s i$, nos seus saberes, valores e crenças, mas na relação com o exterior, com o outro, que o determina, com olhar às condições de produção dos discursos e as formações discursivas de cada dizer do usuário do sistema de saúde sobre seu problema apresentado (MERHY, 2002; FERREIRA, 2001). Na grade curricular das formações em saúde, o espaço para discussões sobre cuidado, políticas de saúde e o SUS ainda é restrita, com momentos pontuais e em determinados períodos da formação. $\mathrm{O}$ profissional sai graduado com qualificação em métodos diagnósticos, fisiopatologia e tratamento, porém sem saber como cuidar dentro de uma dinâmica em que haja visibilidade do sujeito e qual o espaço que ele ocupa neste processo. Para que isto ocorra ele terá que estar atento à linguagem e aos significantes do outro, que está diante de si, e buscar enxergar todas as formas que operam neste cuidado. Aprender com o usuário no encontro, na inter-relação, num movimento contínuo no processo de cuidar, que pode levar à ruptura com o modelo estruturado. Cada profissional pode questionar o interdiscurso na tuberculose, que reproduz os discursos universais, fundamentados no controle, regulação, julgamentos, e possibilitar aos sujeitos, no momento da interação, a produção de um cuidado compartilhado.

O cuidado emerge da relação que se estabelece, do vínculo, como o descrito por Mauss, se dá dentro das práticas sociais (na aproximação e na interação - dar/receber e retribuir), considerando como um "fato social total" - explica-se pelo valor da circulação das coisas entre indivíduos, grupos e não pelo constrangimento, poder, resistência, que afasta ou reprime. O profissional de saúde tem que trabalhar para saúde, necessita disponibilizar o tempo de ouvir o outro, mesmo com a presença de forças, tensão entre o cuidador e o sujeito no momento do adoecimento, para construir a relação fundamentada na reciprocidade. É a dádiva de Mauss, "dar, receber e retribuir", como no Dom de Godbout, as dádivas sempre vão e voltam. Não importa o valor, sua natureza, se idênticas ou não, 
que se reproduzam como no espelho. A devolução da dádiva é explicada pela força presente na "coisa dada". Reciprocidade supõe uma preocupação pelo outro. Não se pode estar inquieto ao outro sem se preocupar com suas condições de existência (ABOURIN, 2008).

Cuidar é se disponibilizar a compreender as condições de existência e reciprocidade (produzir valores afetivos ou éticos, como paz, confiança, amizade e compreensão mútua), sem exercer ação sobre o outro. Na reciprocidade, estabelece-se a relação no processo sem que seja a execução direta da ação, e sim acontece a "inter-ação". Sugere a preocupação em si com o que é ofertado ao outro. É perguntar a si próprio, se o cuidado ao sujeito com TBP e ao sujeito em tratamento para ILTB está envolvido numa relação de reciprocidade ou troca. Deseja-se a reciprocidade, pois a troca remete ao sentido de trazê-lo a sua confiança, alicerçados no discurso da quebra da cadeia de transmissibilidade, para que ele consiga adquirir algo, como tratar, curar e possibilitar a conquista de indicadores. O que estamos fazendo quanto a este cuidado? Cuidando ou nos protegendo? A troca, nesse caso, inverte o movimento da reciprocidade, porque descarta a preocupação com o outro, e busca preferencialmente, a satisfação do próprio interesse. "... Aí chegaram pra nós nos dando uma folha, uma prancheta: "Olha, você lê e se estiver de acordo você assina." Aí eu: "Mas como assim?!?”... "Olha, pelo que tá aqui, é como se eu fosse cobaia de um projeto! De uma experiência! Aí ela deu meio um sorriso, né?"(A1) (ABOURIN, 2008).

Na sequência discursiva acima, tem-se a relação de poder: num primeiro momento, temse a interpelação do profissional de saúde pela ideologia do discurso na tuberculose, cumprimento das diretrizes da pesquisa estabelecidas para avaliação dos contatos - 0 "assujeitamento". Não se identifica alguém voltado ao cuidado, se disponibilizar ao encontro com o sujeito contato de tuberculose, num movimento de reciprocidade, estabelecer vínculo com usuário sem colocá-lo numa situação infantilizada, incapacitado de compreensão e discussão sobre seu projeto terapêutico, ao apresentar uma proposta terapêutica, fria, dura, marcado pela linguagem gestual ao lhe entregar o documento para ser lido e assinado. A entrevistada A1 assume uma relação de tensão e força com o sistema institucionalizado, a posição de ação, não subjugada ao imposto, traz o sentido ideológico no seu discurso, se recusa ao "assujeitamento" ao protocolo. Na sua narrativa, destaca-se o esquecimento ideológico, retorna ao sentido pré-existente, não se submeterá a medicamentos ou tecnologias trazidas de outro país, não entrará numa gaiola como cobaias, aponta para o sentido de laboratório, de colonização, submissão aos processos e ser conduzida. Ela busca orientações, argumentos, respeito, e como estar no mundo, e ser condutor de sua vida. Assim, como não obteve a reciprocidade no encontro com o profissional, não aceitou a terapêutica ofertada, pois o valor da dádiva não é ligado ao uso ou à troca, mas ao vínculo, ao relacional, reforçando a compreensão interacionista da dádiva. A doença TBP e o processo de prevenção não podem ser maiores que o valor das relações do usuário em si mesmo e com o trabalhador da saúde, e sim caracterizado pela reciprocidade, o Dom - sistema de dádiva - descrito por Mauss, com a utilização como caráter sociológico e não religioso (MARTINS, 2008; ORLANDI, 2013).

Ressalta-se que, embora o sistema da dádiva seja mais nítido no plano das relações interpessoais - nas redes de famílias, amigos e vizinhos, tal sistema tende, igualmente, a se fazer presente em todos os planos da vida social, mesmo naquele das sociabilidades secundárias, isto é, no plano das relações funcionais - nos aparelhos políticos, 
econômicos e científicos, mediante uma expectativa de reciprocidade, de confiança implícita a respeito da continuidade da relação que é alimentada subjetivamente pelas pessoas envolvidas.

Assim, no atendimento ao sujeito adoecido por tuberculose e aos seus familiares, o trabalhador da saúde deve estabelecer a dádiva- "dar, receber e retribuir" - em que o projeto terapêutico possa ser construído com todos os atores do processo. Busca-se romper a prática verticalizada, institucionalizada e mecânica, estabelecendo alianças concretas entre os sujeitos com TPB ou ILTB e suas vivências, sendo reconhecidos como sujeitos e cidadãos, e também desfazer a limitação imposta pelo sistema de saúde quando definimos o sujeito como doente.

O sujeito manifesta pelo seu discurso, o contexto ao qual está inserido e não só o agravo de saúde como expressão biológica. O trabalhador da saúde e o sujeito cuidado são interpelados por suas ideologias, que podem ser mutuamente compreendidas no momento da construção da inter-relação, num sistema de respeito mútuo. Por um lado, o usuário com suas experiências e responsabilidades diante da vida e do autocuidado, por outro o cuidador em saúde com atenção ao cuidado integral, olhar plural aos sujeitos nas suas individualidades, respeito às diferenças, aberto às intersubjetividades, lutando diariamente e confrontando os processos de enquadramento do tratamento na tuberculose. $\mathrm{Na}$ busca diária pelo cuidado executado com pensamento crítico, será o caminho intermediário, entremeio, nas relações, na mediação, com o envolvimento da sociedade e do Estado, que tem por dever assumir sua função para a garantia do desenvolvimento do cuidado nas unidades de saúde, em todos os níveis de assistência, que será possível vislumbrar um "mundo sem tuberculose" (MARTINS, 2008).

\section{CONSIDERAÇÕES FINAIS}

$\mathrm{Na} \mathrm{AD}$, analisamos outros olhares, caminhos e movimentos dos discursos. $\mathrm{O}$ estudo possibilitou o deslocamento de sentidos na tuberculose, que apesar ter uma circulação do discurso marcada no diagnóstico, no controle do tratamento, na vigilância, atinge sujeitos que nos apresentaram que suas vidas estão imersas no seu cotidiano e na sua historicidade, e não exclusivamente na doença.

No atendimento diário ao sujeito contatos de TBP, percebe-se que em algumas situações, as atividades sistematizadas e protocolares, não fazem nele uma ressonância esperada, pois o cuidado está além das fronteiras limitadas ao conceito exclusivo do medicamento, do tempo de tratamento e de metas a serem atingidas.

A análise de discursos dos sujeitos que estiveram em acompanhamento ambulatorial, se desloca para outros sentidos, e destaca a importância do trabalhador da área da saúde no processo de cuidar e de se re-engendrar no cotidiano de atuação. É no encontro, que o sujeito irá participar do seu projeto terapêutico, com seus saberes e seu olhar qualitativo, onde o valor não está apenas na doença, mas na sua existência e nas relações por ele constituídas. O valor está no e para o sujeito.

Os estudos do discurso possibilitam entrelaçar o conhecimento em saúde com a heterogeneidade discursiva do sujeito, como percebem a tuberculose, o adoecimento e a 
prevenção a partir das suas vivências, sua história, sua ideologia, e as diferentes formações discursivas presentes nas narrativas, inclusive o interdiscurso biomédico do medo da morte, da transmissão, do combate à doença. Neste contexto, os profissionais do cuidado devem observar no cuidado, os movimentos, os sinais, as pistas, os sons produzidos e os silêncios dos sujeitos, que também querem ser visíveis no processo terapêutico. E assim, compartilhar os entremeios da tuberculose e compreender que a descontinuidade do tratamento da ILTB não é maior que a vida, e que a classificação atribuída ao sujeito como abandonador do processo é restritiva, e o limita como produtor de seus dizeres, preceptor do seu adoecimento, da importância do seu estranhamente, e de sua tomada de decisão diante do que lhe é instituído.

\section{REFERÊNCIAS}

ABOURIN, Eric. Marcel Mauss: da dádiva à questão da reciprocidade. Revista Brasileira de Ciências Sociais, v. 23, n. 66, p. 131-138, fev.2008.

AGUIAR, R. Programa de controle de contatos de tuberculose no Hospital Universitário Clementino Fraga Filho. Dissertação. Mestrado em Clínica Médica, Universidade Federal do Rio de Janeiro, 2014.

BORGHIN, C.M.S. de O.; OLIVEIRA, R.M.; SEVALHO, G. Determinação ou determinantes sociais da saúde: texto e contexto na América Latina. Trabalho, Educação e Saúde, v. 16, n. 3 , 869-897, set./dez. 2018.

BOURDIEU, P. O poder simbólico. Lisboa: DIFEL, 1989.

BRASIL. Governo Federal. Constituição Brasileira. Disponível em: http://www.senado.gov.br/legislacao/const/con1988/CON1988 07.05.2015/art 196 .shtm.

Acesso em:12/04/2019

BRASIL. Ministério da Saúde. Secretaria de Vigilância em Saúde. Departamento de Vigilância das Doenças Transmissíveis. Manual de Recomendações para o Controle da Tuberculose no Brasil / Ministério da Saúde, Secretaria de Vigilância em Saúde, Departamento de Vigilância das Doenças Transmissíveis. Brasília: Ministério da Saúde, 2018.

BREIHL, J. Epidemiologia crítica: ciência emancipadora e interculturalidade. Rio de Janeiro: Fiocruz, 2006.

CDC. Centers for Disease Control and Prevention, U.S. Department of Health and Human Services, Division of Tuberculosis Elimination. Latent Tuberculosis Infection: a Guide for Primary Health Care Providers. 2013. Disponivel em http://www.cdc.gov/tb/publications/ltbi/pdf/targetedltbi.pdf. Acesso em 12 de abril 2019.

COURTINE, J.-J. Análise do discurso político: o discurso comunista endereçado aos cristãos. São Carlos: EDUFSCAR, 2009.

DAGOGNET, F. O corpo. Rio de Janeiro: Forense, 2012.

FERNANDES, C.; VINHAS L.I. Da maquinaria ao dispositivo teórico-analítico: a problemática dos procedimentos metodológicos da Análise do Discurso. Linguagem em (Dis)curso, Tubarão, SC, v. 19, n. 1, 133-151, jan./abr. 2019.

FERREIRA, M.C.L.; GODOY, A.B. et. al. Glossário de Termos do Discurso. Projeto de Pesquisa: A Aventura do Texto na Perspectiva da Teoria do Discurso: a posição do leitor-autor. Porto Alegre: UFRGS. Instituto de Letras, 2001. 30p.

FOUCAULT, M. Aula de 5 de Janeiro de 1983 - Segunda Hora. Em: FOUCAULT, M. O governo de sí e dos outros: curso no Collège de France (1982-1983). São Paulo: Martins Fontes, 2010. p. 25-39.

FOUCAULT, M. Aula de 10 de janeiro de 1979. Em: FOCAULT, M. O nascimento da biopolítica. Curso no Collège de France (1978-1979). São Paulo: Martins Fontes, 2008. 03-31. FREIRE, F.H.M. et. al. Um "estrangeiro" na rede de avaliação compartilhada: experiência em uma área programática no município do Rio de Janeiro. Em: MERHY, E.E. et. al. Política e 
Cuidados em Saúde (LIVRO 1). Avaliação compartilhada do cuidado em saúde: surpreendendo o instituído nas redes. Rio de Janeiro: Hexis, 2016.

GUATTARI, F.; ROLNIK, S. Micropolítica: cartografias do desejo. Petropólis-RJ: Vozes, 1986. GUIMARÃES, E. História, Sujeito, Enunciação. Caderno de Estudos Linguísticos. Campinas, n. 35, jul./dez. 1998. p. 109-116.

MARTINS, P.H. De Lévi-Strauss a M.A.U.S.S - Movimento Antiutilitarista nas Ciências Sociais. Intinerários do dom. Revista Brasileira de Ciências Sociais, v. 23, n. 66, feveiro 2008.

MERHY, E.E. Um ensaio sobre o médico e suas valises tecnológicas: fazendo um exercício sobre a reestruturação produtiva na produção do cuidado. São Paulo: Hucitec, 2002.

MONTAÑO, C.; DURIGUETTO, M.L. Estado, classe e movimento social. $3^{\text {a }}$. ed. São Paulo: Cortez, 2011.

ORLANDI, E.P. Discurso em Análise: sujeito, sentido e ideologia. $3^{\text {a }}$. ed. Campinas: Pontes, 2017.

ORLANDI, E.P. Análise de Discurso: principios e procedimentos. 11 a . ed. Campinas: Pontes, 2013.

ORLANDI, E.P. As formas do silêncio: no moviemto dos sentidos. $6^{\text {a }}$. ed. Campinas: Ed. da Unicamp, 2007.

PÊCHEUX, Michel. Semântica e Discurso: uma crítica à afirmação do óbvio. Trad. Bras. $4^{\mathrm{a}}$. ed. Campinas: Ed. da Unicamp, 2009.

RAVANELLO, T.; DUNKER, C.; BEIVIDAS, W.. Para uma concepção discursiva dos afetos: Lacan e a semiótica tensiva. Psicologia: Ciência e Profissão, v. 38, n. 1, 172-185, 2018.

SILVA, A.C. et. al. (Org.). Por uma ética do cuidado. Rio de Janeiro: Garamond, 2009.

TFOUNI, L.V.; MONTE-SERRAT, D.M.; CHIARETTI, P. (Orgas.). A Análise do Discurso e suas interfaces. São Carlos: Pedro \& João, 2011. p. 146-149.

WASSER, N. Resenha: Vidas precárias entre normalização e movimentação. Sociologias. Porto Alegre, 41, n.18, 364-373, jan./abr. 2016.

Artigo recebido em: ago. de 2019.

Aprovado e revisado em: dez. de 2019.

Publicado em: dezembro de 2019.

Para citar este texto:

LEUNG, Janaina Aparecida de Medeiros; CUNHA, Fátima Teresinha Scarparo; KRITSKI, Afranio Lineu. Na tuberculose, como cuidar? Entremeios [Revista de Estudos do Discurso, ISSN 2179-3514, on-line, www.entremeios.inf.br], Seção Estudos, Programa de Pós-Graduação em Ciências da Linguagem (PPGCL), Universidade do Vale do Sapucaí (UNIVÁS), Pouso Alegre (MG), vol. 19, p. 63-78, jul. - dez. 2019.

DOI: http://dx.doi.org/10.20337/ISSN2179-3514revistaENTREMEIOSvol19pagina63a78 